\title{
Family Structure Histories and High SchoOl Completion: Evidence FROM A PopUlation-BASED REgistry
}

\author{
LisA STROHSChEIN \\ Noralou Roos \\ MARNI BROWNELL
}

\begin{abstract}
This paper uses a life course approach to investigate the association between family structure histories and high school completion. Using data from a population-based data registry for the 1984 Manitoba birth cohort, we selected a sample of children born or adopted at birth into a married two-parent household $(n=9,403)$ and derived family structure histories for each child to the age of 18 . Marital disruption occurred for 1,834 children (19.5\%), with 337 children (3.6\% of the total sample) experiencing multiple changes in family structure. Logistic regression models showed that children who experienced marital dissolution before the age of 18 were significantly less likely to complete high school than children in intact households, and that children who were younger at the time of a first transition were more vulnerable than children who were older when their parents' marriage ended. Further work is needed to elucidate the pathways that link family structure histories to child outcomes.
\end{abstract}

Key Words: divorce, high school graduation, marital instability

Résumé. Le but de cette communication consistait à utiliser une approche tirée de la vie pour examiner la relation entre les antécédents en termes de structure familiale et l'obtention du diplôme d'études secondaires. En utilisant les données d'un registre basé sur la population de la cohorte de naissance de $1984 \mathrm{du}$ Manitoba, nous avons pris un échantillon d'enfants nés, ou adoptés à la naissance, dans un ménage de deux parents mariés $(n=9,403)$ et les antécédents en termes de structure familiale pour chaque enfant jusqu'à l'âge de 18 ans. Des perturbations matrimoniales se sont produites dans le cas de 1834 enfants (19,5 $\%$ ), et 337 enfants (3,6\% de l'échantillon total) ont vécu des changements multi-

* This research was supported by an RBC Financial Group visiting fellowship to Lisa Strohschein (HIPC No. 2005-17). Special thanks to Randy Walld and Leonard MacWilliam at MCHP for data analysis; Marina Yogendran and Bogdan Bogdanovic also provided assistance. Results and conclusions presented are those of the authors. No official endorsement by Manitoba Health and Healthy Living is intended or should be inferred. 
ples dans la structure familiale. Les modèles de régression logistiques indiquent que les enfants qui vivent une perturbation matrimoniale avant l'âge de 18 ans étaient considérablement moins enclins à terminer leurs études secondaires que les enfants de ménages intacts. Les enfants qui étaient plus jeunes au moment de la première transition étaient plus vulnérables que les enfants qui étaient plus âgés lors de la fin du mariage de leurs parents. D'autres recherches sont nécessaires pour élucider les voies reliant les antécédents de structure familiale aux résultats des enfants.

Mots clefs: le divorce; remise des diplômes d'école secondaire; instabilité maritale

Families represent one of the most important mechanisms for the transmission of human and social capital with implications for intergenerational mobility and a successful transition to adulthood (Biblarz and Raftery 1993; Musick and Mare 2004). Changes in family composition, evidenced by increases in both marital instability and nonmarital childbearing over the past 30 years (Seltzer 2000), have raised questions about the consequences for children's achievements. An ongoing debate among researchers who investigate the relationship between family structure and educational outcomes involves discerning whether it is the type of family a child lives in (family structure) or the stress of adapting to a marital transition (family instability) that matters most. Although there is evidence to support each position, their shared weakness is an inability to locate family structure and family instability within the context of a complete family structure history.

In this paper, we apply a life course approach to better articulate the influence of family structure histories on high school completion. We use data from a population-based data registry for the 1984 Manitoba birth cohort to select a sample of children born or adopted at birth into a married two-parent household. We construct family structure histories for each child, paying attention to the type and timing of changes in family structure that transpire from birth to the age of 18 and derive variables that capture the marital history of parents prior to the birth of the child. We then test which aspects of these family structure histories predict high school graduation by the age of 20 .

\section{BACKGROUND}

\section{Family Structure or Family Instability?}

Studies that compare educational outcomes across family types assessed at only one point during childhood generally find that children 
in single-parent households are less likely to complete high school relative to children in intact two-biological-parent households (Astone and McLanahan 1991; Deleire and Kalil 2002; Ermisch and Francesconi 2001; Evans, Kelley and Wanner 2001; Haveman, Wolfe, and Spaulding 1991; McLanahan and Sandefur 1994). These differences are attributed to structural deficiencies inasmuch as living in a single-parent household is associated with greater economic hardship and the absence of an additional authority figure to provide attention and supervision. The literature demonstrates, however, that it is more than just parental absence: children living in step-parent households also fare more poorly in school than children in two-biological-parent households (Biblarz and Gottainer 2000; Evans et al. 2001). It has been suggested that children living in step-parent households may not benefit from the additional income and supervision that a step-parent potentially brings to the household, if the step-parent must divert resources to nonresident children from previous relationships (Manning and Smock 1999), or if children must compete with the step-parent for the attention of the biological parent (Booth and Dunn 1994).

Criticism that snapshot assessments of family structure do not adequately represent the dynamic aspects of household composition over the course of childhood has led some researchers to advocate for the importance of family instability (Hill, Yeung, and Duncan 2001). Changes in family structure are viewed as stressful events that require parents and children to renegotiate and reorganize their relationships and their lives. Whether a child lives in a single-, step-, or two-biological-parent household at one point in time is seen as less influential than the upheaval that marital instability introduces into children's lives (Fomby and Cherlin 2007). Studies that follow children as they experience changes in family structure show that children whose parents were married at initial interview but later divorce are less likely to finish high school than children whose parents remain married (Painter and Levine 2000; Pong and Ju 2000; Sun and Li 2001). Less support is found for the family instability perspective when considering the effects of remarriage on educational attainment, as outcomes are not significantly worse for children in which a remarriage occurs relative to children in households that remain divorced (Painter and Levine 2000).

The limitation of these studies is that they evaluate change in family structure over a short period of time, typically during adolescence. As a result, researchers have a limited number of transitions to evaluate. In addition, assessing family instability during the adolescent period prevents researchers from taking into account any prior changes in family structure. In other words, such studies assume that children who occupy 
the same family structure at the beginning of the study also have similar family histories.

From this vantage point, it appears that researchers from both the family structure and the family instability perspective share a common weakness: they treat as equivalent children who live in the same family structure at one point in time, but have family histories that are radically different. For example, by treating single parenthood as a homogenous category, researchers ignore the different routes by which children enter into such households (McKay and Rowlingson 1998). Although the majority of single-parent households are formed through marital dissolution, rates of nonmarital childbearing are steadily increasing: nearly $10 \%$ of Canadian children in the 1990s were born into never married motherheaded households (Juby, Marcil-Gratton, and LeBourdais 2005). This difference is important because children born into single-parent households experience both greater marital instability and more persistent poverty on average than children born into married parent households that later divorce (Juby, Marcil-Gratton, and LeBourdais 2001; McLanahan and Sandefur 1994; Seltzer 2000).

Boundaries are also blurred when researchers do not evaluate the different routes out of marriage. McLanahan and Sandefur (1994) suggest that the death of a parent may not be as damaging to children as divorce because the consequences associated with parental death do not entail the same level of residential mobility, economic hardship, or exposure to ongoing conflict that occurs among children whose parents divorce. Their analysis of several national cross-sectional surveys using retrospective measures of family structure revealed that high school completion rates among children who experienced parental death were not significantly different from children in continuously intact households, with children of divorce reporting significantly lower rates than either group. More recently, Biblarz and Gottainer (2000) showed that children whose parents divorced were significantly less likely to complete high school relative to children who lost a parent through death.

The distinction between parental death and divorce is also important because researchers can compare differences in outcomes between the two groups to determine whether the effects of divorce might be spurious. That is, some researchers have argued that the observed relationship between parental divorce and educational outcomes may not be causal, but due to unobserved factors such as poverty and parental conflict that are predictive of both divorce and reduced educational attainment. Corak (2001) argues that parental loss through death should be less correlated with unobserved family characteristics than parental divorce. To the extent that parental death is exogenous, it operates as a 
benchmark that provides unbiased estimates for the effects of parental loss on child outcomes.

In short, there is a need for research that moves beyond the debate between family structure and family instability and distinguishes among the different types of transitions that are experienced over the course of childhood. A life course approach makes the argument that family structure at any given point in time must be understood within the context of prior life experiences. Although studies that adopt a life course perspective have broadened the perspectives of researchers in this area and introduced important new ideas, there has been much less progress in understanding the ways in which family instability and family structure are connected.

\section{A Life Course Approach}

Formally described by Elder (1998), a life course approach posits that human lives unfold in social time and space, but are also lived interdependently. Socially meaningful events alter life's pathways not just for that individual, but for those connected to that individual. Two key concepts of a life course approach stand out when considering the effects of family structure on educational outcomes. First, a life course approach suggests that family transitions occur within the context of a long-term pattern of prior experiences and circumstances that, in turn, influence future opportunities. When a child's experiences of family structure are assessed over the entirety of childhood, what emerges are patterns of stability and change that can be reliably differentiated into trajectories (George 1993). These trajectories provide the context for understanding the consequences of occupying a given family structure, but also reflect the types of transitions that children are likely to experience. The characteristics of the trajectories themselves, including the timing of transitions and the cumulative effect of multiple changes in family structure, are analytically useful in understanding how family histories influence educational outcomes. Exploring these aspects, research has shown that the younger the age of a child at the time of a change in family structure, the greater the risk that child will not finish high school (Ermisch and Francesconi 2001; Ermisch, Francesconi and Pevalin 2004; Krein and Beller 1988; Zill, Morrison and Coiro 1993). Others have found that each change in family structure from birth until adolescence results in a corresponding increase in the odds of dropping out of high school (Cavanagh, Schiller, and Riegle-Crumb 2006).

As with studies locked in debate over the importance of family structure versus family instability, studies that investigate the timing and 
number of transitions rarely differentiate among the types of transitions. Of the two studies that specifically incorporate a life course perspective, Heard (2007) distinguishes between early versus late transitions, whereas Cavanagh and her colleagues (2006) simply count the number of transitions during the childhood period. Because both studies utilize samples with children whose family structure at birth varies, a transition in either study necessarily stands for both gains and losses. For example, households that are coded as having experienced a single transition include those with children born to a single mother who enters and remains in a first marriage as well as children born into a two-parent household that experiences parental divorce but no further change. Underlying these analyses then is an approach that prioritizes the influence of family instability over family structure, but does not explore the connections between them.

A second key concept in a life course approach is the notion of linked lives. Individuals move through life together, forming intimate relationships and developing social bonds that not only regulate patterns of social interaction, but create ripple effects when events occur to any one individual within a socially bonded group. Indeed, conducting research to show that parents' marital histories shape a child's educational achievements exemplifies the idea of linked lives (Cavanagh et al. 2006). However, the concept of linked lives also implies that the marital history of a parent, even prior to the birth of a child, can affect the life chances of that child. First, marital instability is greater among those who have been previously married, so children born to parents who were in previous relationships are more likely to experience parental divorce compared to children born into households where parents are in their first marriage. Moreover, if a prior union produced children, parental attention and resources may be diverted from children in the current household to children from past relationships. It is likely, then, that parents with marital relationships that predate the birth of a child, and particularly parents with relationships that produced children, exert a dampening influence on the educational outcomes of children from the current household relative to parents who are both in their first marriage when the child is born.

To summarize, studies are needed that fully embrace a life course approach to enhance our understanding of how family structure and family instability are connected to educational outcomes. We seek to accomplish this task by restricting our analysis to children who share a common start by being born into a married parent household. The disadvantage of this strategy is that our findings will not be generalizable to children who are born into single-parent or cohabiting-parent households; the strength is that we can be much more precise in testing whether parental death, di- 
vorce, remarriage, and multiple transitions exert different effects on educational outcomes for children who are born into married households. We are also interested in expanding the boundaries of the concept of linked lives by exploring whether parental marital relationships prior to the birth of a child matter for that child's educational attainment.

Using data from a population-based registry of all children born or adopted at birth into married two-parent households in the province of Manitoba in 1984, we document patterns of continuity and change in family structure over the entire childhood period. We then test five hypotheses about the effect of family structure histories on high school completion. First, we hypothesize that changes in family structure lower children's chances of completing high school relative to children who remain in married parent households. We also evaluate whether losing a parent through death is comparable to parental divorce in its effect on high school completion. Similar to Corak (2001), we use a difference-indifferences estimator to evaluate whether high school completion rates for children of divorce are significantly different than those for children from bereaved families. Our third hypothesis tests whether the effect of changes in family structure is cumulative, making children who experience three or more changes in family structure less likely to complete high school than children who report two transitions. Fourth, we hypothesize that high school completion rates will be higher for children whose parents are in their first marriages compared to a higher order marriage for one or both parents. We also distinguish between prior unions that produced children and those that did not, because children from previous relationships may divert resources away from the current household. Finally, we hypothesize that the younger the age of the child at the time of the first transition into a single-parent household, the lower the likelihood that child will complete high school.

\section{Methods}

\section{Sample}

Housed at the Manitoba Centre for Health Policy, the Manitoba Population Health Research Registry is an administrative, population-based dataset that has collected health care information on all residents of Manitoba since 1970. Residents are assigned an encrypted identifying number that maintains patient confidentiality, but allows researchers to derive longitudinal histories that record each contact with the health care system as well as date of birth and death, sex, household composition, and place of residence. Time-sensitive elements such as changes 
in household composition are updated using "snapshot" registries provided by the ministry of Manitoba Health and Healthy Living every six months. Because Manitoba Health and Healthy Living relies on respondent notification of a change in marital status, there is some error in our measure of marital change, which is a limitation we later discuss. Beginning in 1995, administrative data from the Manitoba Ministry of Education were transferred to the Repository, allowing for analysis of educational outcomes.

Our initial sample consists of all children born in the province of Manitoba in 1984, who resided continuously in the province until the age of $18(n=12,636)$. To select children who were at risk for marital dissolution, we restricted our analysis to children who were born or adopted at birth into married two-parent households $(n=9,906,78.4 \%)$. We were unable to consider children born into cohabiting households in our study because we could not reliably identify such households (too few households in 1984 self-identified as cohabiting). In households recording multiple births, we randomly selected one child from each household. Missing values occurred only for educational outcomes and resulted in the elimination of 413 cases, producing a final sample of 9,403 children.

\section{Measures}

\section{High school completion}

Our dependent variable assesses high school status in the sixth year after a student first registers in grade 9. After six years, students are classified as either graduated, withdrawn, or still progressing. Students are graduated if they have the required courses for graduation or Manitoba Education has assigned a graduation flag to their file. Students are considered withdrawn if they do not have the required courses to graduate by their sixth year and have not been enrolled in high school in the last two years. Still progressing refers to those students who do not have enough courses to graduate in their sixth year but were enrolled in high school in their fifth and/or sixth year. Preliminary analysis with a three-level dependent variable showed no significant differences between withdrawn and still progressing students on any of the explanatory variables. Consequently, we combined still progressing with withdrawn into a single category. Our dependent variable is coded 1 if the student has graduated high school and 0 otherwise.

\section{Family structure histories}

Using the updated six-month registry from birth to the age of 18 , we constructed detailed family structure histories for each child in our sample. 
From these histories, we created the three variables needed to test our hypotheses: family histories from birth to age 18 , marital history of the child's parents prior to 1984, and age of the child at time of first marital transition.

\section{Family history from birth to age 18}

We derived five mutually exclusive and exhaustive categories for changes in family structure that occur in our sample of children from birth to age 18. Dummy variables were constructed for parental divorce only, parental death only, parental death or divorce followed by remarriage, and three or more transitions, with remaining in a married parent household acting as the omitted reference category. Children who experienced three or more transitions were combined into a single category because of the small number of children with more than three changes in family composition.

\section{Marital history prior to 1984}

Marital histories of the male and female parent prior to the birth of the child in 1984 were constructed with two dummy variables that reflect prior marital unions that did not produce any children $(1=$ yes; $0=$ no $)$ and prior marital unions that did produce children $(1=$ yes; $0=$ no $)$. The omitted reference category is neither parent had a prior marital union.

\section{Age of the child at time of first change in family structure}

We used an internal moderator of the child's age at time of first change in family structure to test the hypothesis that the age at which a child first experiences marital disruption affects high school graduation. We centred the variable for age at time of first transition around the mean age at which these children experienced a transition. A score of 0 (the mean) was assigned to children whose households remained intact on this internal moderator variable. ${ }^{1}$

\section{Control variables}

All models control for demographic characteristics of the child and family that are predictive of high school graduation. Sex of the child is a dummy variable that is coded 1 for male children, and 0 otherwise. The number of children in the household is a count of all the live children born to the mother. Birth order is a discrete variable that reflects the order of birth, with higher numbers representing later births. Mother's age

1. The construction and interpretation of internal moderator variables, also known as conditionally relevant variables, are described in detail elsewhere (Ross and Mirowsky 1992; McDonough and Strohschein 2003). 
at birth of first child is a continuous variable representing the age of the mother at the birth of her first child. We centred all continuous variables around their respective mean values.

\section{Analysis}

We used logistic regression models to evaluate the effect of family histories on the odds of completing high school, adjusting for sex and birth order of the child, as well as the number of children and mother's age at birth of first child.

\section{Results}

Table 1 presents characteristics for each of the five constructed family histories in our analysis. Of 9403 children, 7569 children (80.5\%) did not experience any change in family structure between birth and age 18 . For those with only one change in family structure, 1325 children (14.1\% of total sample) experienced parental divorce, and 172 children (1.8\%) experienced parental death. Two transitions (remarriage following marital dissolution) occurred for 285 children (3.0\%), whereas 52 children $(0.6 \%)$ experienced three or more changes in family structure between birth and age 18 .

Child characteristics varied according to their family history. Children in households that experienced parental death with no further change were later in the birth order relative to children in households with no change in marital status. Relative to mothers in households that remained married, the age of mother at birth of first child was significantly lower in households that divorced but had no further change in family structure and households with multiple transitions. Households that remained intact also experienced fewer marital transitions prior to 1984 than children experiencing changes in family structure (with the exception of households that experienced two transitions where differences failed to be significant at $\mathrm{p}<.01$ ). That is, $10.3 \%$ of households that remained intact between 1984 and 2002 had at least one parent with a marital relationship prior to 1984 compared to $48 \%$ of households that reported three or more changes in family structure between 1994 and 2002. As expected, age of the child at time of first change in family structure was related to family history. Children who experienced parental divorce but no further transitions were significantly younger at the time of divorce than children who reported parental death but no further transitions, but significantly older than children reporting multiple transitions. The proportion of children graduating from high school is highest 
Table 1. Child and Family Characteristics by Family History, 1984 Birth Cohort, Children Born or Adopted into a Married Two-parent Household, Manitoba Population Health Registry ( $N=9403)$.

\begin{tabular}{|c|c|c|c|c|c|}
\hline & $\begin{array}{l}\text { Parents } \\
\text { remain } \\
\text { together }\end{array}$ & $\begin{array}{l}\text { Parental di- } \\
\text { vorce, no fur- } \\
\text { ther change }\end{array}$ & $\begin{array}{c}\text { Parental } \\
\text { death, no fur- } \\
\text { ther change }\end{array}$ & $\begin{array}{l}\text { Parental death/ } \\
\text { divorce and } \\
\text { remarriage }\end{array}$ & $\begin{array}{c}\text { Three or } \\
\text { more tran- } \\
\text { sitions } \\
\end{array}$ \\
\hline Child is male & 51.0 & 49.4 & 54.6 & 48.1 & 51.9 \\
\hline Birth order & $\begin{array}{c}2.0 \\
(1.1)\end{array}$ & $\begin{array}{c}2.0 \\
(1.1)\end{array}$ & $\begin{array}{r}2.5^{\mathrm{a}} \\
(1.7)\end{array}$ & $\begin{array}{c}1.9 \\
(1.3)\end{array}$ & $\begin{array}{c}2.0 \\
(1.2)\end{array}$ \\
\hline $\begin{array}{l}\text { Number of } \\
\text { children in } \\
\text { household }\end{array}$ & $\begin{array}{c}3.0 \\
(1.5)\end{array}$ & $\begin{array}{c}3.0 \\
(1.5)\end{array}$ & $\begin{array}{c}2.9 \\
(1.4)\end{array}$ & $\begin{array}{c}2.9 \\
(1.4)\end{array}$ & $\begin{array}{c}3.1 \\
(1.5)\end{array}$ \\
\hline $\begin{array}{l}\text { Mother's age } \\
\text { at birth of first } \\
\text { child }\end{array}$ & $\begin{array}{l}24.4 \\
(4.3)\end{array}$ & $\begin{array}{r}22.8^{\mathrm{a}} \\
(4.3)\end{array}$ & $\begin{array}{l}24.0 \\
(4.9)\end{array}$ & $\begin{array}{l}22.0^{\mathrm{a}} \\
(3.8)\end{array}$ & $\begin{array}{l}21.5^{\mathrm{a}} \\
(3.8)\end{array}$ \\
\hline \multicolumn{6}{|l|}{$\begin{array}{l}\text { Marital status } \\
\text { prior to birth of } \\
\text { child }\end{array}$} \\
\hline $\begin{array}{l}\text { No marital } \\
\text { unions prior to } \\
\text { birth of child }\end{array}$ & 89.7 & $81.6^{\mathrm{a}}$ & $82.0^{\mathrm{a}}$ & 84.9 & $52.0^{\mathrm{a}}$ \\
\hline $\begin{array}{l}\text { In a prior } \\
\text { marriage that } \\
\text { produced no } \\
\text { children }\end{array}$ & 7.7 & $14.0^{\mathrm{a}}$ & 11.0 & 11.2 & $28.8^{\mathrm{a}}$ \\
\hline $\begin{array}{l}\text { In a prior mar- } \\
\text { riage that pro- } \\
\text { duced children }\end{array}$ & 2.6 & $4.4^{\mathrm{a}}$ & $7.0^{\mathrm{a}}$ & 3.9 & $19.2^{\mathrm{a}}$ \\
\hline Child age at & NA & 8.5 & $10.1^{\mathrm{b}}$ & $5.4^{\mathrm{b}}$ & $3.5^{\mathrm{b}}$ \\
\hline transition & & $(4.5)$ & (4.9) & (3.6) & (2.5) \\
\hline $\begin{array}{l}\text { Graduated from } \\
\text { high school }\end{array}$ & 78.4 & $56.4^{\mathrm{a}}$ & $61.6^{\mathrm{a}}$ & $64.2^{\mathrm{a}}$ & $40.4^{\mathrm{a}}$ \\
\hline$N$ & 7569 & 1325 & 172 & 285 & 52 \\
\hline
\end{tabular}

Note: Statistics are reported as means (SD) and proportions. NA=not applicable

a significantly different from households that remain together $(\mathrm{p}<.01)$

$\mathrm{b}$ significantly different from households that divorce, with no further change $(\mathrm{p}<.01)$

for children with no change in family structure (78.4\%) and lowest for children with three or more changes in family structure (40.4\%).

Results from logistic regression models are presented in Table 2 . The odds of graduating were significantly lower for male relative to female children, for children who were born later in the birth order relative to those born earlier, and for children whose mothers were younger when their first child was born (Model 1). Relative to children in households that reported no change in marital status, children who experienced any type of change in family structure were less likely to graduate from high school. For example, the odds of completing high school for children whose parents experienced parental divorce but no further changes in 
family structure were $61 \%$ lower $(100 *[.39$ - 1]) than for children whose parents remained together. We conducted post hoc tests employing a difference-in-differences estimator to evaluate whether the odds of graduating high school differed between children whose parents divorced compared to children who lose a parent through death, but found no significant differences $\left(\chi^{2}=1.47, \mathrm{df}=1, \mathrm{p}<.22\right)$. There were also no significant differences in the odds of graduating for children with one marital transition versus two marital transitions; however, we found that children with three or more changes in family structure were significantly less likely to finish high school than children with two changes in family structure $\left(\chi^{2}=7.88, \mathrm{df}=1, \mathrm{p}<.01\right)$. The marital histories of parents prior to the birth of the child in 1984 were not significant predictors of high school graduation.

In Model 2, we tested the hypothesis that the effect of changes in family structure on high school graduation depends on child age at the time of first transition. Comparing the goodness of fit, we found that the

Table 2. Effect of Family Histories on High School Graduation by Age of 20, 1984 Manitoba Birth Cohort, Children Born or Adopted into a Married Two-parent Household ( $N=9403)$.

\begin{tabular}{|c|c|c|c|c|c|c|}
\hline \multirow[b]{2}{*}{ Variable } & \multicolumn{3}{|c|}{ Model 1} & \multicolumn{3}{|c|}{ Model 2} \\
\hline & $b$ & se & Odds & $b$ & se & Odds \\
\hline Intercept & 1.63 & & & 1.63 & & \\
\hline Male child & $-.51 * * *$ & $(.05)$ & .60 & $-.51 * * *$ & $(.05)$ & .60 \\
\hline Birth order & $-.19 * * *$ & $(.02)$ & .83 & $-.19 * * *$ & $(.02)$ & .83 \\
\hline Number of children in household & .01 & $(.02)$ & 1.01 & .01 & $(.02)$ & 1.01 \\
\hline $\begin{array}{l}\text { Mother's age at birth of first child } \\
\text { Family history }^{\mathrm{a}}\end{array}$ & $.11 * * *$ & $(.01)$ & 1.12 & $.11 * * *$ & $(.01)$ & 1.12 \\
\hline Divorce, no remarriage & $-.94 * * *$ & $(.06)$ & .39 & $-.95^{* * *}$ & $(.07)$ & .39 \\
\hline Death of a parent, no remarriage & $-.72 * * *$ & (.17) & .49 & $-.78 * * *$ & (.17) & .46 \\
\hline $\begin{array}{l}\text { Parental death/divorce and remar- } \\
\text { riage }\end{array}$ & $-.58 * * *$ & (.13) & .56 & $-.50 * * *$ & (.14) & .61 \\
\hline Three or more transitions & $-1.47 * * *$ & $(.29)$ & .23 & $-1.35^{* * *}$ & $(.30)$ & .26 \\
\hline $\begin{array}{l}\text { One or both parents previously } \\
\text { married, but no children from pre- } \\
\text { vious marriage }\end{array}$ & -.15 & $(.11)$ & .86 & -.17 & $(.11)$ & .84 \\
\hline $\begin{array}{l}\text { One or both parents previously } \\
\text { married with children from previ- } \\
\text { ous marriage }^{\mathrm{b}}\end{array}$ & -.02 & $(.17)$ & .98 & -.03 & $(.17)$ & .97 \\
\hline $\begin{array}{l}\text { Age of child at time of first change } \\
\text { in family structure }\end{array}$ & & & & $.03 *$ & $(.01)$ & 1.03 \\
\hline - 2 Log Likelihood & 9774.59 & & & 9768.38 & & \\
\hline $\mathrm{df}$ & 10 & & & 11 & & \\
\hline
\end{tabular}


addition of the term for child age at time of first transition significantly improved the fit of the model $(\Delta-2 \mathrm{LL}=6.21, d f=1, p<.01)$. The positive term for child age suggests that the older the age of the child at time of first transition, the weaker the effect of a change in family structure. Because marital change at an early age makes it possible for parents to experience further marital transitions, adding child age at the time of first marital transition has the effect of increasing the size of the coefficients for one marital change and dampening the effect of multiple transitions.

\section{Discussion}

Social scientists have a longstanding interest in investigating how families facilitate the educational attainment of their offspring. As family forms become more diverse and family histories more complex, the consequences of these transformations for the development and wellbeing of Canadian children have also become important issues for policymakers and the general public. Our study contributes to current knowledge by applying a life course approach to evaluate whether the type, number, and timing of changes in family structure influence educational outcomes for children born or adopted at birth into married parent households.

We found support for most of our hypotheses. First, as expected, children who experienced any change in family structure during childhood were significantly less likely to complete high school compared to children whose parents remained married. Given that any child who experiences a change in family structure necessarily lost a parent at some point during childhood, our analysis confirms that parental loss reduces children's chances of finishing high school. We did not find, however, that there were differences in educational attainment for children whose parents divorced compared to children who experienced the death of a parent. This result contradicts two studies based on American data that find children whose parents divorce are significantly less likely to complete high school than children who are bereaved (Biblarz and Gottainer 2000; McLanahan and Sandefur 1994). Our findings are more similar to those of a Canadian study, albeit using slightly different outcomes. Corak (2001) reported that there were no differences in the labour market earnings of those who as children experienced bereavement versus divorce. That there were no differences in the effects of bereavement and divorce on educational attainment provides further support to the argument that parental loss is a factor in impeding academic progress.

Our hypothesis about the cumulative effects of multiple changes in family structure directly addresses the family instability hypothesis. Existing evidence already suggests that high school completion rates 
for children in remarried households are not significantly different from children who experienced marital dissolution (Painter and Levine 2000), making it unlikely that each additional change in family structure produces the same effect on educational outcomes. The results of our study correspond with the findings of Painter and Levine, but we are also able to show that children who experienced the breakup of this second marital relationship experienced significantly lower rates of high school completion relative to children whose remarried household remained intact. It appears that two loss events have a much more devastating effect on educational attainment than experiencing marital dissolution but no further changes in family structure or parental loss followed by a stable remarriage. Our results give greater credence to parental loss rather than marital instability as a predictor of high school completion. The implication of this finding is that researchers may make inaccurate conclusions about the association between the number of transitions a child experiences during childhood and high school completion if it is assumed that the relationship is linear or if researchers fail to distinguish among the types of transitions children experience.

The results of this study did not support our hypothesis that parental marital history prior to the birth of the child has an effect on educational outcomes. Although we expected to find that children whose parents had previous marital relationships, particularly unions that produced children, would be less likely to finish high school, our results indicated there were no significant differences relative to children born to parents in their first marriages. Even so, our results do speak to the important principle of linked lives in that children who experienced marital disruption between birth and age 18 were significantly less likely to have parents who were in their first marriage compared to children whose parents remained together from birth to age 18. In this way, we do note that children's life chances, as exhibited in the family structures that they are likely to occupy during childhood, are shaped by their parents' marital history prior to their own birth. Moreover, we believe that our data undercounts changes in marital status, therefore, further work is needed to more rigorously test whether marital relationships prior to the birth of a child are indeed irrelevant to that child's educational attainment.

Finally, we found evidence to support our hypothesis that children who experience marital disruption at a young age are at greater risk for not completing high school relative to children who are older at the time of the first change in family structure. This corresponds with other studies that report the effect of divorce on educational outcomes is greater for younger than older children (Ermisch and Francesconi 2001; Ermisch et al. 2004; Heard 2007; Krein and Beller 1988; Zill et al. 1993). We note 
that at least two studies do not confirm this pattern, however, with one study finding that timing is unrelated to high school graduation (Haveman et al. 1991) and another reporting that the effect of a change in family structure is stronger for older than for younger children (Garasky 1995). Although our results suggest that changes in family structure early in life set these children on a different trajectory of educational experiences, researchers have yet to determine why younger children are more vulnerable. It may be that younger children have fewer emotional skills to deal with stressful events, or that children who experience transitions at an earlier age are more likely to spend a longer period of time without adequate supervision, or simply that earlier transitions increase the likelihood of subsequent changes in family structure. Research that can account for the vulnerability of younger children remains an important area for future investigation.

In sum, we argue that a life course approach is critical to investigating the links between family structure and educational outcomes because it allows researchers to see family structure and family instability as interconnected processes, rather than competing explanations. Measures that can capture the complexity of a family structure history over the entire childhood period present a more comprehensive picture than snapshot assessments of family structure at one point in childhood or prospective studies that evaluate changes in family structure over a limited time span. Moreover, the construction of these family structure histories enables researchers to explore whether distinctive features such as the type, number, and timing of changes in family structure over the course of childhood exert a unique influence on high school completion.

By focusing specifically on children who shared a common start by being born or adopted at birth into a married two-parent household, we arrive at the provocative finding that parental loss may be more important for high school completion than family instability. Because this countervails the current preference among family researchers for a family instability perspective (Fomby and Cherlin 2007), replicating this finding in subsequent research and testing the influence of family structure histories on educational outcomes for children born into a single or cohabiting parent household are key areas for future research.

\section{Limitations}

While one strength of administrative data is the ability to track detailed marital and birth histories over a 30 year period, the accuracy with which events are recorded is a potential limitation of our work. There is little longitudinal research in Canada on changes in family structure during 
childhood, but we were able to use findings from two large national surveys to gauge the accuracy of our family structure measures. A comparison of marital status measures in the Registry to self-reported responses made by Manitobans who also participated in the 1996 National Population Health Survey (NPHS) suggests overall good agreement. Notably, 94\% of those who reported being married in the NPHS were recorded as married in the Registry (sensitivity), whereas $85 \%$ of those who were not married in the NPHS were correctly recorded as not married in the Registry (specificity). Applying these findings to our sample selection strategy, it is likely that we failed to include a number of children who were born into married-parent households, but are not recorded as such.

This assessment is borne out by findings drawn from the National Longitudinal Survey of Children and Youth (NLSCY). Juby and her colleagues (2005) report that $87 \%$ of children born in 1983-84 in the prairie provinces, which includes Manitoba, were born into marriedparent households. Because children in the current study were also born in 1984, our findings are directly comparable. The discrepancy between the $78 \%$ of all births in married-parent households identified in our study and the $87 \%$ reported by Juby and her colleagues makes clear that we failed to include a sizeable number of children who were actually born into a married-parent household.

Comparing our rates of marital instability with findings from the NLSCY, it is also likely that we have undercounted the actual number of changes in family structure in at least two ways. First, using the 1983-84 birth cohort from the NLSCY, Juby and her colleagues (2005) report that nearly $30 \%$ of children born into a two-parent household experienced marital dissolution by the age of 15 . Although their estimates include cohabiting relationships, which are known to be less stable than marriages, our estimate that $19.5 \%$ of children born into married-parent households experience marital dissolution by age 18 is surely an undercount. Moreover, Wu and Schimmele (2003) note that more than half of Canadians who experience marital dissolution will repartner within five years, with the majority choosing to enter cohabiting rather than marital unions. In our analysis, less than a fifth of the sample reports entering into a union after marital dissolution. This suggests that there are a number of parents who have been misclassified as experiencing only one marital transition, but who are likely to have entered subsequent unions, including unreported common law relationships.

We are unable to determine the extent to which these errors bias our estimates of family structure histories on graduating from high school. Similar analysis with different data should be undertaken to determine whether our findings can be replicated. 
A second limitation of this study is that we cannot shed light on the role of structural processes such as poverty nor internal family dynamics such as parental conflict that might provide a much richer understanding of the ways in which family structure histories are related to educational outcomes. To the extent that poverty acts as an impediment to staying married and to the upward mobility of one's children, one might argue that the links between family structure histories and educational outcomes more accurately represent selection effects. At the same time, changes in family structure may precipitate entry into poverty and multiple changes in family structure may interfere with the ability to accumulate resources as quickly as continuously married households, with corresponding effects on educational attainment. Because we do not have measures of household income in our data, we cannot determine whether economic disadvantage operates as a logically prior causal factor and/or as a mediating variable that explains the effect of changes in family structure on educational attainment. These same arguments also extend to internal family processes. Until researchers know more about the quality of family life within different family types, it would be premature to conclude that marital disruption necessarily jeopardizes children's life chances. Indeed, prior research suggests that, in families that are highly dysfunctional, divorce represents escape from a toxic environment that leads to improvements in child wellbeing (Strohschein 2005). Making use of other data sources that can disentangle these complex relationships is just one of the recommendations we have for future research that we discuss in the next section.

\section{Future Directions}

Although our study advances knowledge by revealing the influence of family structure histories on educational outcomes, there is a need to uncover the underlying causal mechanisms in this relationship. We have already mentioned household income and family processes, but another plausible candidate involves residential mobility which has been linked on its own to grade failure (Simpson and Fowler 1994) and dropping out of high school (Haveman et al. 1991). Relocation may enhance opportunities when families move to more advantaged neighbourhoods, but residential mobility is also a common consequence of marital instability, as when the departure of a parent from the household is accompanied by changes in neighbourhoods and schools. In such situations, children may become disconnected from the positive socializing influence of teachers as well as other adult role models in their neighbourhoods of origin. Understanding the influence of residential mobility and other stressful 
events that occur as a result of changes in family structure is an important area for future research.

A second area for future research would be to use information on all children born in the same household to deal with the issue of unobserved heterogeneity. That is, the effect of family structure on children's achievements may be spurious due to the mutual association that family structure and child outcomes share with some unmeasured true causal factor (such as household income). When information has been gathered on all children who at any point share the same household, family-specific fixed effects models present a reasonable solution. Specifically, sibling-difference estimates control for more aspects of family background than conventional reduced form models, meaning that estimates will be less contaminated by unmeasured factors that are associated with both family structure and children's outcomes. Studies that attempt to resolve the issue of unobserved heterogeneity have so far been inconclusive, with some finding that the effects of family structure persist (Hao and Xie 2002) and others finding that they do not (Aughinbaugh, Pierret, and Rothstein 2005). Given that the Manitoba Population Health Research Registry contains information on all children, future work with siblingeffects models represents a logical next step.

Finally, as Canadian families continue their retreat from traditional patterns of marriage, there is a need to evaluate how family structure histories affect the life chances of children born into single-parent and cohabiting households. While we have mapped family structure histories for children born or adopted at birth into married two-parent households, concern about the accuracy of measures of marital status in the Registry prevented us from constructing family structure histories for children born into other kinds of households. Finding data sources that allow researchers to capture the complex histories of children across the range of different family structures they are born into is a critical task, and one that has important policy implications. For example, if the family instability hypothesis is correct, then children born into stable cohabiting or stable single-parent households should do as well as children who grow up in stable, married, two-parent households. In that context, the recent wave of marriage-promotion policies enacted in the United States to encourage poor, single mothers to get married may prove to be misguided and ineffectual for improving children's life chances (Furstenberg, 2007). Similarly, if entry into marriage produces minimal gains, but parental loss delivers devastating effects for children born to single and cohabiting parent households, then any effort to introduce marriage promotion programs in Canada requires compelling evidence that such programs meaningfully translate into stable (and satisfying) unions for 
its participants. Otherwise, such programs may unwittingly place children at greater risk.

\section{REFERENCES}

Astone, N.M. and S.S. McLanahan. 1991. Family structure, parental practices and high school completion. American Sociological Review 56:309-20.

Aughinbaugh, A., C.R. Pierret, and D.S. Rothstein. 2005. The impact of family structure transitions on youth achievement: Evidence from the children of the NLSY79. Demography 42(3):447-68.

Biblarz, R.J. and A.E. Raftery. 1993. The effects of family disruption on social mobility. American Sociological Review 58:97-109.

Biblarz, T.J. and G. Gottainer. 2000. Family structure and children's success: A comparison of widowed and divorced single-mother families. Journal of Marriage and the Family 62:533-548.

Booth, A. and J. Dunn. 1994. Stepfamilies: Who Benefits? Who does not? Hillsdale, N.J.: Laurence Erlbaum Associates.

Cavanagh, S.E., K.S. Schiller, and C. Riegle-Crumb. 2006. Marital transitions, parenting, and schooling: Exploring the link between family-structure history and adolescents' academic success. Sociology of Education 79:329-354.

Corak, M. 2001. Death and divorce: The long-term consequences of parental loss on adolescents. Journal of Labor Economics 19(3):682-715.

Deleire, T. and A. Kalil. 2002. Good things come in threes: Single-parent multigenerational family structure and adolescent adjustment. Demography 39(2):393-413.

Elder, G.H., Jr. 1998. The life course as developmental theory. Child Development 69:1-12.

Ermisch, J. and M. Francesconi. 2001. Family structure and children's achievements. Journal of Population Economics 14:249-70.

Ermisch, J., M. Francesconi, and D.J. Pevalin. 2004. Parental partnership and joblessness in childhood and their influence on young people's outcomes. Journal of the Royal Statistical Society A 167(1):69-101.

Evans, M.D.R., J. Kelley, and R.A. Wanner. 2001. Educational attainment of the children of divorce: Australia, 1940-1990. Journal of Sociology 37(3):275-297.

Fomby, P. and Cherlin, A.J. 2007. Family instability and child well-being. American Sociological Review 72:181-204.

Furstenberg, F.F., Jr. 2007. Should government promote marriage? Journal of Policy Analysis and Management 26(4):956-61. 
Garasky, S. 1995. The effects of family structure on educational attainment: Do the effects vary by the age of the child? American Journal of Economics and Sociology 54(1):89-105.

George, L.K. (1993). Sociological perspectives on life transitions. Annual Review of Sociology 19:353-373.

Hao, L. and G. Xie. 2002. The complexity and endogeneity of family structure in explaining children's misbehavior. Social Science Research 31:1-28.

Haveman, R., B. Wolfe, and J. Spaulding. 1991. Childhood events and circumstances influencing high school graduation. Demography 28(1):133-157.

Heard, H.E. 2007. Fathers, mothers and family structure: Family trajectories, parent gender and adolescent schooling. Journal of Marriage and Family 69:435-50.

Hill, M.S., W.J. Yeung, and G.J. Duncan. 2001. Childhood family structure and young adult behaviors. Journal of Population Economics 14:271-299.

Juby, H., N. Marcil-Gratton, and C. LeBourdais. 2005. When Parents Separate: Further Findings from the National Longitudinal Survey of Children and Youth. Ottawa: Department of Justice Canada. (2001). A step further in family life: The emergence of the blended family. Report on the Demographic Situation in Canada-2000. Ottawa: Statistics Canada. Cat: 91-209.

Krein, S.F. and A.H. Beller. 1988. Educational attainment from single parent families: Differences by exposure, gender and race. Demography 25(2):221-34.

Manning, W.A. and P. Smock. 1999. New families and nonresident father-child visitation. Social Forces 78(1):87-116.

McDonough, P. and L. Strohschein. 2003. Age and the gender gap in distress. Women and Health 38(1):1-20.

McKay, S. and K. Rowlingson. 1998. Choosing lone parenthood? The dynamics of family change. In F. Reuben and J. Millar, eds., Private Lives and Public Responses: Lone Parenthood and Future Policy in the UK. London: Policy Studies Institute.

McLanahan, S. and G. Sandefur. 1994. Growing Up with a Single Parent: What Hurts, What Helps. Cambridge, MA: Harvard University Press.

Musick, K. and R.D. Mare. 2004. Family structure, intergenerational mobility, and the reproduction of poverty: Evidence for increasing polarization? Demography 41(4):629-648.

Painter, G. and D.I. Levine. 2000. Family structure and youths' outcomes: Which correlations are causal? Journal of Human Resources 35(3):524-549.

Pong, S. and D. Ju. 2000. The effects of change in family structure and income on dropping out of middle and high school. Journal of Family Issues 21(2):147-69. 
Ross, C.E. and J. Mirowsky. 1992. Households, employment and the sense of control. Social Psychology Quarterly 55:217-35.

Seltzer, J.A. 2000. Families formed outside of marriage. Journal of Marriage and Family 62:1247-1268.

Simpson, G.A. and M.G. Fowler. 1994. Geographic mobility and children's emotional/behavioral adjustment and school functioning. Pediatrics 93(2):303-309.

Strohschein, L. 2005. Parental divorce and child mental health trajectories. Journal of Marriage and Family 67:1286-1300.

Sun, Y. and Y. Li. 2001. Marital disruption, parental investment and children's academic achievement: A prospective analysis. Journal of Family Issues 22(1):27-62.

Wu, Z. and C. Schimmele. 2003. Repartnering after first union disruption. Journal of Marriage and Family 67:27-36.

Zill, N., D.R. Morrison, and M.J. Coiro. 1993. Long-term effects of parental divorce on parent-child relationships, adjustment and achievement in young adulthood. Journal of Family Psychology 7(1):91-103.

Lisa Strohschein is assistant professor in the department of sociology at the University of Alberta. Her research interests include investigating the influence of stressful life events such as parental divorce and economic hardship on child health and development.

Noralou Roos is professor in the department of Community Health Sciences, Faculty of Medicine at the University of Manitoba. As the Founding Director of the Manitoba Centre for Health Policy her research interests focus on the use of administrative data for understanding the broader determinants of population health and well-being.

Marni Brownell is an associate professor in the Department of Community Health Sciences at the University of Manitoba, and senior researcher at the Manitoba Centre for Health Policy. Her research focuses on the social determinants of child health and development. 
